\title{
Antioxidant Activity from Baccaurea lanceolataMuell. Arg fruit
}

\author{
$1^{\text {st }}$ Kunti Nastiti ${ }^{1}, 2^{\text {nd }}$ Samsul Hadi ${ }^{2}, 3^{\text {rd }}$ Subagus Wahyuono $^{3}, 4^{\text {th }}$ Endang Lukitaningsih ${ }^{3}$ \\ (kuntinastiti86@gmail.com ${ }^{1}$, samsul.hadi.apt@gmail.com ${ }^{2}$, lukitaningsih_end@yahoo.com³ \\ ${ }^{1}$ Departement of health, Universitas Sari Mulia \\ ${ }^{2}$ Department of Pharmacy, Universitas Lambung Mangkurat \\ ${ }^{3}$ Faculty of Pharmacy, Universitas Gadjah Mada
}

\begin{abstract}
Fruits of Baccaurealanceolata is commonly used by tribe banjar in south Borneo to protect the skin damages due to sun light. People apply the pulverized fruits to the skin that will be exposed to sunlight. Antioxidant bioassay method (DPPH) is used to prove the effectiveness of the fruits.Baccaurealanceolata fruitsvwere extractedby $70 \%$ ethanol, followed by fractionation with n-hexane, ether, ethyl acetate and methanol to give n-hexane $(\mathrm{fr}-\mathrm{H})$, ether (fr. $\mathrm{Et}_{2} \mathrm{O}$ ), ethyl acetate (fr.EtOAc) and methanol (fr. $\mathrm{MeOH}$ ) fractions respectively. Preparative TLC $\left(\mathrm{SiO}_{2}\right)$ of the fr.EtOAc that showed the the highest antioxidant activity among those fractions. This compound was active as antioxidant $1.124 \mathrm{mg} / \mathrm{ml}$.
\end{abstract}

Keywords: Baccaurealanceolata, antioxidan, $\beta$-Sitosterol

\section{Introduction}

The local wisdom of the Banjar tribe in South Kalimantan is truly extraordinary in terms of health and beauty. Not only the Indonesian people who take advantage of this potential, but foreign communities also use it (Uluk et al., 2001).

The Banjar tribe that lives around the forests in South Kalimantan until now still maintain the tradition by utilizing the surrounding plants for treatment or health care. One of the uses of natural materials by the Banjar tribe is Limpasu fruit (Baccaurealanceola) which comes from the Limpasu tree and is commonly used for skin care. This fruit is used when they will go to the fields by applying it to the skin with the aim of protecting the skin from the sun. UV rays from the sun have a fairly strong energy and can ionize the atoms in the layer of the atmosphere, so that it is classified as radiation that is harmful to human skin if emitted in a large intensity. UV light can cause the formation of free radicals and trigger oxidative stress if the formation of ROS (Reactive Oxygen Species) exceeds the ability of endogenous antioxidant defense systems (Katiyar et al., 2010). To overcome the presence of free radicals in the skin caused by sunlight, one of the tests that can conducted on the overflowing fruit that is the DPPH radical capture test approach. 


\section{Methodology}

\subsection{Tools}

L Acura ${ }^{\circledR} 825$ (Socorex, Switzerland), Duran ${ }^{\circledR}$ enclosed test tubes (Schott North America Inc., USA), separating funnel $500 \mathrm{~mL}$, round bottom flask (Schott North America Inc., USA), heating mantle, ultrasonic device, centrifugation device, homogenizer, and glassware, UV-Vis spectrophotometer (Perkin Elmer Inc., USA), quartz silica cuvette (Sigma Chem. Co., USA), efendorf, analitical balance and semi micro balance BP 160P (Sartorius, USA), electric Scaltec SBC 22 (Microprecision Caliberacion Inc. , USA), waterbath, micropipette 0.5

\subsection{Material}

Baccaurea lanceolata, methanol p.a; chloroform p.a; ethyl acetate p.a; n-hexane p.a; methanol. Ethyl acetate, ether, n-hexane. Silica gel 60 PF254 containing gypsum, Aluminum TLC (Thin Layer Chromatography), chromatographic plates, DPPH, ascorbic acid. Isolation

\section{Extraction}

Baccaurea lanceolata extracted with $70 \%$ alcohol, fractionated with n-hexane, ether, ethyl acetate and methanol to produce fraction of n-hexane ( $\mathrm{fr}-\mathrm{H})$; ether fraction (fr-E); ethyl acetate fraction (fr-EA) and methanol fraction (fr-M). Based on the activity test (DPPH), fr-EA is the most active fraction as an antioxidant with an IC50 value of $230 \mu \mathrm{g} / \mathrm{ml}$, so it is fractionated with VLC (Vacuum liquid Chromatography) and obtained 18 fractions. Based on the similarity of the TLC image, the fractions with similar TLC profiles are combined to obtain 3 fractions (fr-EA1; frEA2; fr-EA3). fr-EA3 has an IC50 (DPPH) of $158 \mu \mathrm{g} / \mathrm{ml}$ so that isolation is done by the KLTP method and isolates are obtained. Anti oxidant potential was measured.

\section{Anti-antioxidant test with DPPH method}

The compounds that have been separated by isolation by KLTP are tested for antioxidant activity using the Kwon and Kim method (Kwon and Kim, 2003). The isolate solution in chloroform at several concentrations, as much as $1.2 \mathrm{~mL}$ plus $0.3 \mathrm{~mL}$ of DPPH $0.4 \mathrm{mM}$ solution in chloroform so that the total volume of the mixture was $1.5 \mathrm{~mL}$ and the mixture was shaken strongly. After settling at room temperature for 30 minutes, the remaining DPPH is determined spectrophotometrically at a wavelength of $517 \mathrm{~nm}$. This test also carried out measurements of blank (DPPH solution that does not contain test material) as well as positive control of ascorbic acid. The DPPH radical capture activity $(\%)$ is calculated by the following formula:

DPPH scavenging inhibitory $(\%)=[(\mathrm{A} 0-\mathrm{A} 1) / \mathrm{A} 0] \times 100$

(Note A0: absorption from blanks and A1: absorption from isolates or acids). 


\section{Results and Discussion}

Determine the antioxidant ability, the method used is the DPPH test, because this DPPH test can evaluate the antioxidant ability caused by oxidative stress

Isolate II at a concentration of $400.2 \mu \mathrm{g} / \mathrm{ml} ; 800.8 \mu \mathrm{g} / \mathrm{ml} ; 1201 \mu \mathrm{g} / \mathrm{ml} ; 1601.6 \mu \mathrm{g} / \mathrm{ml}$; $2002.0 \mu \mathrm{g} / \mathrm{ml}$ was significantly different compared to normal control (figure 1) so that this isolate had anti-oxidant activity, with an IC50 value of $1.124 \mathrm{mg} / \mathrm{ml}$.

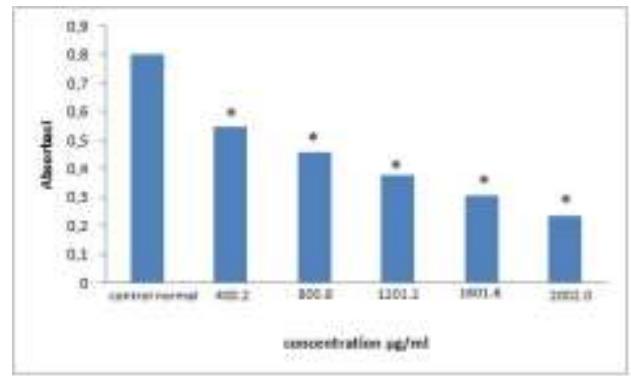

Fig.1.antioxidant isolate II. significance value compared to control $* \mathrm{p}<0.05$.

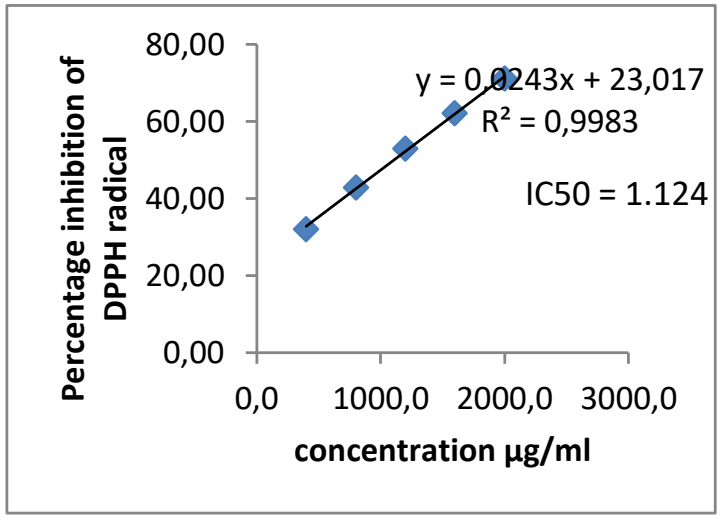

Fig.2. Percent inhibition of isolate II by DPPH method

The Isolate II was estimated a terpenoid compound. The antioxidant ability of triterpenes from other species varies from size $\mu \mathrm{g} / \mathrm{ml}$ or $\mu \mathrm{M}$ to $\mathrm{mg} / \mathrm{ml}$ or $\mathrm{mM}$. Three new triterpenes compounds found from the roots of Momordica charantia have antioxidant activity with IC50 values $268.5 \pm 7.9,352.1 \pm 11.5458 .9 \pm 13.0 \mu \mathrm{M}$ (Liu., Et al 2009). Chilianthin B, chilianthin C, and chilianthin A from Betula platyphylla var. japonica bark shows the antioxidant ability with IC50 between 4.48-43.02 $\mu \mathrm{M}$ by DPPH method (Eom et al., 2016). Triterpenic glycoside 3-O(beta-D-glucopyranosyl) -hederagenin isolate from Hedera colchica has the ability of antioxidant activity $30 \mu \mathrm{g} / \mathrm{ml}$ (Gulcin., Et al., 2006). Oleanolic acid isolated from Viscum articulatum, Burm. (Loranthaceae) has antioxidant abilities and inhibits the release of nitric oxid seen in plasma nitrate / nitrite (Bachhav et al., 2011). Anti-radical effect of Lantadene A from Lantana by DPPH method has antioxidant activity IC50: $0.027 \mathrm{mg} / \mathrm{ml}$; with hydroxyl radicals IC50: $0.937 \mathrm{mg} / \mathrm{ml}$; 
Superoxide anion radical IC50: $1,025 \mathrm{mg} / \mathrm{ml}$, with nitric oxide radicals IC50 $=0.075 \mathrm{mg} / \mathrm{mL}$ (Chong et al., 2012). The antioxidant activity of KopsiasingapurensisRidl triterpenes is more than $500 \mu \mathrm{g} / \mathrm{mL}$ containing lupeol, lupeol acetate, $\beta$-amyrin, $\beta$-amyrin acetate, $\beta$-amyrone, Stigmasterol (Shan, et al., 2014). F1 fraction of Ganoderma lucidum has higher antioxidant activity compared to other fractions with IC50 $0.90 \mathrm{mg} / \mathrm{ml}$, this is positively correlated with total

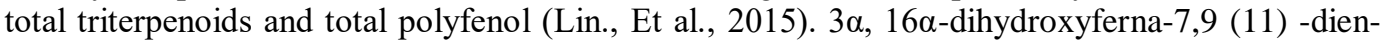
12-one isolated from Lonicera quinquelocularis have antioxidant activity better than other isolates

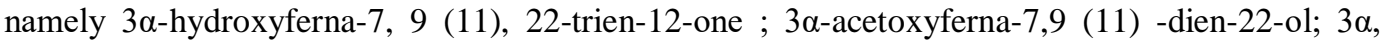
16 $\alpha$-dihydroxyferna-8-en-11-one (Khan et al., 2014).

\section{Conclusion}

With the guided DPPH Bioassay method, antioxidant activity of Isolate II with IC50 $1124,125 \pm 0,729 \mu \mathrm{g} / \mathrm{ml}$ was classified as weak.

\section{References}

[1] Funayama, S.; Noshita, T.; Shinoda, K.; Haga, N.; Nozoe, S.; Hayashi, M.; Komiyama, K. Cytotoxic alkaloids of Pachysandra terminalis. Biol. Pharm. Bull. 23: 262-264 (2000).

[2] Kwon, Y.S., \& Kim, C.M. Antioxidant Constituent from the Stem of Sorghum bicolor. Arch. Pharm. Res. 26 (7) : 535-539 (2003).

[3] Gülçin I, Mshvildadze V, Gepdiremen A, and Elias R. The antioxidant activity of a triterpenoid glycoside isolated from the berries of Hedera colchica: 3-O-(beta-D-glucopyranosyl)-hederagenin. Phytother Res.20(2):130-4 (2006).

[4] Sheng Yi and Xiao-Bin Chen. Isolation and identification of an isomer of $\beta$-sitosterol by HPLC and GC-MS. Health .1:203-206 (2009).

[5] Liu C.H., Ming-Hong Yen, Shih-Fang Tsang, Kim-Hong Gan, Hsue-Yin Hsu, Chun-Nan Lin. Antioxidant triterpenoids from the stems of Momordica charantia..Food Chemistry .118(3):751-756 (2010).

[6] Bachhav SS, Patil SD, Bhutada MS, Surana SJ. Oleanolic acid prevents glucocorticoid-induced hypertension in rats. Phytother Res.25(10):1435-9 (2011).

[7] Chaturvedula, V.S.P., Prakash, I. Isolation of Stigmasterol and $\beta$-Sitosterol from the dichloromethane extract of Rubussuavissimus. International Current Pharmaceutical Journal, 1(9): 239-242 (2012).

[8] Chong Grace-Lynn, Ibrahim Darah, Yeng Chen, Lachimanan Yoga Latha, Subramanion L. Jothy and SreenivasanSasidharan. In Vitro Antioxidant Activity Potential of Lantadene A, a Pentacyclic Triterpenoid of Lantana Plants Molecules 17:11185-11198 (2012).

[9] Manullang, L., Daniel and Enos TangkeArung, Toxicity Test And Antioxidant Fruit Extracts Kelepesoh (Baccaurealanceolata(Miq.) Mull. Arg), J. Science east Borneo, 1:75- 82 (2013).

[10] Abu Bakar M.F. Nor Ezani Ahmad, Fifilyana Abdul Karim andSyazlinaSaib . PhytochemicalsandAntioxidativePropertiesof Borneo IndigenousLiposu (Baccaurealanolata) and Tampoi (Baccaureamacrocarpa) Fruits. Antioxidants3: 516-525 (2014) 
[11] Shan., L.Y., Tee Chuan Thing, Tan Siow Ping, Khalijah Awang, Najihah Mohd Hashim, Mohd Azlan Nafiah and Kartini Ahmad. Cytotoxic, antibacterial and antioxidant activity of triterpenoids from Kopsiasingapurensis Ridl. J. Chem. Pharm. Res. 6(5):815-822 (2014).

[12] Khan D., Masood Afzal1, Simon Woodward and Shafiullah Khan. Two New Antioxidant Triterpenoids from Lonicera quinquelocularis. Rec. Nat. Prod. 8(2) :121-127 (2014).

[13] Lin M., zer-ran Yu, Be-jen Wang, Cheng-chi wang, Yin-ming Weng and Malcolm. Bioactive Constituent Characterization and Antioxidant Activity of Ganoderma lucidum Extract Fractionated by Supercritical Carbon Dioxide. SainsMalaysiana. 44(12): 1685-1691 (2015).

[14] Eom HJ, Kang HR, Kim HK, Jung EB, Park HB, Kang KS, Kim KH. Bioactivity-guided isolation of antioxidant triterpenoids from Betula platyphylla var. japonica bark.Bioorg Chem. 66:97-101 (2016). 